\title{
Towards PHA production from wastes: The bioconversion potential of different activated sludge and food industry wastes into VFAs through acidogenic fermentation
}

\section{Gabriela Montiel-Jarillo}

Universitat Autònoma de Barcelona: Universitat Autonoma de Barcelona

\section{Teresa Gea}

Universitat Autònoma de Barcelona: Universitat Autonoma de Barcelona https://orcid.org/0000-00032523-4797

\section{Adriana Artola}

Universitat Autònoma de Barcelona: Universitat Autonoma de Barcelona https://orcid.org/0000-00020524-2119

\section{Javier Fuentes}

Universitat Autònoma de Barcelona: Universitat Autonoma de Barcelona

\section{Julián Carrera}

Universitat Autònoma de Barcelona: Universitat Autonoma de Barcelona https://orcid.org/0000-00022599-2312

\section{Maria Eugenia Suárez-Ojeda ( $\square$ mariaeugenia.suarez@uab.cat )}

Universitat Autònoma de Barcelona: Universitat Autonoma de Barcelona https://orcid.org/0000-00032520-2701

\section{Research Article}

Keywords: volatile fatty acids, polyhydroxyalkanoates, acidogenic fermentation, oil cake

Posted Date: April 6th, 2021

DOl: https://doi.org/10.21203/rs.3.rs-341352/v1

License: (9) This work is licensed under a Creative Commons Attribution 4.0 International License. Read Full License

Version of Record: A version of this preprint was published at Waste and Biomass Valorization on May 26th, 2021. See the published version at https://doi.org/10.1007/s12649-021-01480-4. 


\section{Abstract}

Acidogenic fermentation of wastes produces volatile fatty acid (VFA)-rich streams that can be used as low-cost carbon sources for polyhydroxyalkanoate (PHA) production. In this study, an inoculum collected from an anaerobic reactor of a municipal WWTP was conditioned to suppress methanogenic activity. The heat-shock conditioning method of the inoculum proved to be more efficient than acid and alkaline conditioning methods for methanogen inhibition. Then, the pre-conditioned inoculum was used to determine the acidogenic potential of different wastes: three waste activated sludge (WAS) samples generated at different sludge retention times (SRTs, 2, 7 and 14 days), olive mill wastewater (OMW), glycerol, apple pomace (AP) and winterization oil cake (WOC). Batch tests were performed in quintuplicate at $37^{\circ} \mathrm{C}$ and $\mathrm{pH} 7$. A higher degree of acidification was observed for high-rate activated sludge ( 2 days of SRT) $(69 \%)$, followed by olive mill wastewater (OMW) (43\%), while the lowest was for glycerol (16\%). The results for the winterization oil cake (WOC) samples interestingly elucidated a high content of propionic acid with a high odd-to-even ratio $(0.86)$ after fermentation. Feeding the VFA profile obtained from WOC into a PHA production system led to a significant production of $0.64 \mathrm{~g} \mathrm{PHA} \mathrm{g}^{-1} \mathrm{C}$ with $30 \%$ polyhydrobutyrate $(\mathrm{PHB})$ to $69 \%$ polyhydroxyvalerate $(\mathrm{PHV})$ as monomeric units of HB-co-HV, decoupling the need for a related carbon source for co-polymer production.

\section{Statement Of Novelty}

The acidogenic potential of several industrial wastes was assessed with the context of being used as potential precursors for polyhydroxyalkanoate production by evaluating the odd-to-even ratio of the generated volatile fatty acids (VFA) profile. To the best of our knowledge, this is the first time high-rate WAS (2 days of SRT), WOC and AP were fermented with this ultimate objective. The VFA profile obtained from WOC fermentation presented a high odd-to-even ratio (1.2 to 1.3). This mixture was fed into a PHA production system, yielding $0.64 \mathrm{~g} \mathrm{PHA} \mathrm{g}^{-1} \mathrm{C}$ with a composition of $30 \% \mathrm{PHB}$ to $70 \% \mathrm{PHV}$. This mitigates the need for extra carbon sources to adjust the acetic acid to propionic acid proportion for co-polymer production.

\section{Highlights}

Inoculum heat shock provided the best acidogenic conditions

High-rate activated sludge shows a high acidification potential

Winterization oil cake bioconversion led to an odd-to-even ratio close to one An odd-to-even VFA ratio of 1.2 led to a $70 \%$ PHV proportion in the produced PHA.

\section{Introduction}


Polyhydroxyalkanoates (PHAs) are biobased and biodegradable polymers that can be produced by many microorganisms [1]. The thermoplastic properties of PHA are very similar to those of petroleum-based plastics and have therefore been considered interesting materials to replace the use of synthetic plastics [2]. The main obstacle for widespread PHA application is its high production costs compared to those of petroleum-based plastics. The use of mixed microbial cultures (MMCs) allows for the use of a wide range of wastes as precursors, such as molasses, cheese whey, olive mill wastewaters, glycerol, and food waste, for PHA production [2, 3]. For this reason, MMCs have been widely investigated to reduce PHA production costs. The production of PHA using wastes as feedstock normally occurs in a three-stage process that involves i) acidogenic fermentation, ii) culture selection and iii) PHA production [3].

Waste valorization has gained great interest in the last decade due to its potential for energy and marketable chemical recovery, which represents a green and valuable alternative to waste disposal. The organic fraction of industrial and agro-industrial wastes can be fermented into volatile fatty acids (VFAs), alcohols, hydrogen $\left(\mathrm{H}_{2}\right)$, methane $\left(\mathrm{CH}_{4}\right)$ and carbon dioxide $\left(\mathrm{CO}_{2}\right)[4,5]$. The most widely applied treatment for industrial and agro-industrial wastes is anaerobic digestion, which can be divided into two steps: acidogenic fermentation and methanogenesis. Commonly anaerobic digestion has been mainly used to produce methane. However, the presence of intermediates with higher industrial value than methane during acidogenic fermentation, such VFA, has been recognized $[5,6]$.

Volatile fatty acids are considered promising by-products due their potential application as versatile precursors, such as those for the generation of electricity and biobased solvents, preservatives in the food industry, synthesis of pharmaceuticals and chemicals, biological nitrogen removal, biodiesel production and the synthesis of biopolymers and alcohols [5-7].

Volatile fatty acids are well-known precursors for PHA synthesis and thus acidogenic fermentation can be integrated into the PHA production process, which enhances, from an environmental and economic point of view, the overall process $[8,9]$. The composition and properties of the synthesized PHA depend on the VFA chain length and composition. In general, the presence of even-numbered VFAs, such as acetic and butyric acids, resulted in the synthesis of hydroxybutyrate (HB), and odd-numbered VFAs (propionic and valeric acids) hydroxyvalerate (HV) were produced. On the one hand, polyhydroxybutyrate (PHB) polymers are the most widely known biopolymers; however, their applications are limited because they are stiff and brittle. On the other hand, the incorporation of hydroxyvalerate (HV) leads to the synthesis of a copolymer $\mathrm{P}(\mathrm{HB}-\mathrm{co}-\mathrm{HV})$, which is interesting from an industrial point of view, as it is more elastic and flexible $[8,10]$. In this sense, the ratio of odd-to-even VFAs obtained in the acidification of wastes determines the production of a biopolymer with a certain composition; thus, it is essential to determine the valorization potential of those wastes in terms of its degree of acidification and in terms of the composition of the VFA mixture produced.

During acidogenic fermentation, many parameters, such as the carbon/nitrogen $(\mathrm{C} / \mathrm{N})$ ratio, $\mathrm{pH}$, temperature and feedstock composition, influence the yields of $\mathrm{H}_{2}$ and VFA production and composition $[11,12]$. It is feasible to use an anaerobic mixed culture as inoculum for acidogenic fermentation, but 
methanogen activity must be suppressed [13]. For this goal, there are several conditioning methods reported in the literature: chemical inhibitors such as 2-bromoethanesulfonate acid, methyl chloride and lumazine [6, 14]; chemical conditioning such as acid, alkali and organic shock addition; and physical strategies such as heat, freezing and thawing, ultrasound, among others that effectively inhibit methanogens $[13,15]$.

A variety of novel solid and liquid wastes have been used in this research to appraise their acidogenic potential, namely, three waste activated sludge (WAS) samples; olive mill wastewater (OMW), winterization oil cake (WOC) and apple pomace (AP) samples as three industrial wastes; and glycerol. These materials are described below together with their advantages and feasibility:

1. Biological wastewater treatment plants (WWTPs) produce high volumes of WAS, and their treatment and disposal represent, in general, ca. $60 \%$ of the total WWTP costs [16]. Commonly, WAS is treated under anaerobic digestion to produce methane; however, WAS is rich in carbohydrates and proteins and has been considered a suitable substrate to produce $\mathrm{H}_{2}$ [17] and VFAs [18]. Nevertheless, WAS usually requires pre-treatment methods to enhance the achieved acidogenic yields, which are usually low [19].

2. OMW is an abundant biowaste derived from olive oil production mostly in the Mediterranean region and represents an environmental problem due to the high amounts of production and chemical characteristics $[9,20]$. Acidogenic fermentation to obtain VFAs has been proposed as an alternative to valorize OMW $[1,20]$.

3. WOC is an industrial waste generated from wax removal from sunflower oil, safflower oil, canola oil and corn oil and is mainly composed of filtering aid, oil and waxes. WOC is reported to be used as a substrate in solid-state fermentation for the production of lipases [21] and sophorolipids [22], and to the best of our knowledge, this is the first study to explore its acidogenic potential.

4. AP is a highly biodegradable waste resulting from the fruit juice industry and contains saccharides, proteins, vitamins, and organic acids. AP has been used to obtain value-added products such as pectins, enzymes, phenolic compounds, organic acids, ethanol, antioxidants and animal feed, and some studies have exploited its potential for $\mathrm{H}_{2}$ and VFA production [23].

5. Glycerol is a by-product generated during biodiesel production [24] and is considered waste due to its excess availability; thus, novel uses for glycerol have to be developed to avoid its environmental accumulation. The acidogenic potential of glycerol has been previously assessed, as it is considered a versatile raw material for this purpose [10].

The acidogenic potential for all the residues described above was assessed with the main standpoint of being used as potential precursors for PHA production. For that aim, these experiments were strongly focused on the bioconversion of each substrate into VFAs due to their recognition as favourable substrates for PHA production. Moreover, the influence of three inoculum conditioning methods (heat shock and acidic and alkaline conditions) was assessed as conditioning strategies to select the one that most enhances acidogenic conditions. 


\section{Materials And Methods}

\subsection{Inoculum and conditioning strategies}

Anaerobic biomass used as inoculum was collected from an anaerobic reactor of a municipal WWTP (Rubí, Catalonia, Spain), with $10.8 \mathrm{~g} \mathrm{~L}^{-1}$ total solids and $6.3 \mathrm{~g} \mathrm{~L}^{-1}$ volatile solids (VS). The biomass was stored at $4^{\circ} \mathrm{C}$ in a sealed tank without supplying any substrate to inhibit microbial activity from taking place before the fermentation process began. The inoculum was treated by heat-shock, acidic or alkaline conditions to inhibit methanogenic activity. For heat shock, the sludge was heated at $104^{\circ} \mathrm{C}$ for $2 \mathrm{~h}$. Then, the dried sludge was broken with a mortar and pestle, and the resulting powder was used as inoculum [25]. The acid and alkali conditioning methods were performed as described by Zhang et al. [26]. The sludge $\mathrm{pH}$ was adjusted to 3.0-4.0 (acid) or 12.0 (alkali) by adding $1 \mathrm{M} \mathrm{HCl}$ or $1 \mathrm{M} \mathrm{NaOH}$. The sludge was mixed and stirred for $24 \mathrm{~h}$ and then re-adjusted back to $\mathrm{pH}$ 7.0.

\subsection{Assessment of the inoculum conditioning strategies}

Batch experiments were conducted with inoculum biomass that followed different conditioning strategies to assess the inhibition degree of methanogens using glucose and cellulose as model substrates. The experiments were performed anaerobically in $150 \mathrm{~mL}$ glass reactors with a working volume of $140 \mathrm{~mL}$. The biomass was stored under anaerobic conditions at $37^{\circ} \mathrm{C}$ until endogenous conditions were attained before the beginning of the experiments. The initial concentration of inoculum was $6 \mathrm{~g} \mathrm{VS} \mathrm{L}^{-1}$, and the substrate concentration exhibited $9 \mathrm{~g}$ of chemical oxygen demand (COD) $\mathrm{L}^{-1}$. The nutrient medium was prepared as described by Angelidaki et al. [27]. The mixture was bubbled with $\mathrm{N}_{2}$ for approximately 5 min to guarantee anaerobic conditions. A solution of $0.5 \mathrm{~g}$ of cysteine hydrochloride and $2.6 \mathrm{~g}$ of $\mathrm{NaHCO}_{3}$ was prepared in $10 \mathrm{~mL}$ of distilled water and added to the nutrient medium. Twenty millilitres of the nutrient medium was added to each bottle, and distilled water was added to achieve the working volume. The $\mathrm{pH}$ was measured and adjusted to $\mathrm{pH} 7$ by the addition of $1 \mathrm{M} \mathrm{NaOH}$. Finally, each bottle was purged with nitrogen gas for $2 \mathrm{~min}$ and sealed. The reactors were incubated at $37^{\circ} \mathrm{C}$ using a thermostatic incubator (MEMMERT ${ }^{\circledR}$ IN75).

\subsection{Application of the selected conditioned inoculum to assess the acidogenic potential of different wastes.}

Once the best conditioning strategy was established, the treated inoculum was used to determine the acidogenic potential of different wastes: three different waste activated sludge (WAS), olive mill wastewater (OMW), glycerol, apple pomace (AP) and winterization oil cake (WOC). In all experiments, the inoculum-to-substrate ratio was maintained ca. 1, expressed as the ratio between the TS $\left(\mathrm{g} \mathrm{L}^{-1}\right)$ concentration for inoculum and the organic content for substrate ( $\mathrm{g} \mathrm{COD} \mathrm{L}^{-1}$ for WASa, WASb, WASc, OMW and glycerol and \% dry matter for WOC and AP).

The main difference between the three tested WAS samples was the SRT at the wastewater treatment plant at which they were generated. One sample (WASa) was collected from a high-rate activated sludge 
(HRAS) pilot-scale reactor operated with an SRT of 2 days. The other two samples were collected from a conventional activated sludge system of a municipal WWTP (Rubi, Catalonia, Spain) operated at two different SRTs: 7 days (WASb) and 14 days (WASc). OMW was obtained from an olive oil producer (Lleida, Spain), glycerol came from biodiesel production (Montmeló, Spain), WOC was provided by an edible oil refinery (Barcelona, Spain) and AP was collected from a cider industry (Girona, Spain). The characterization of each waste is shown in Table 1.

Table 1 Characterization of wastes used as substrates for anaerobic fermentation.

\subsection{Tests to determine the acidogenic potential of wastes.}

Batch experiments were performed in the same way as described in section 2.2 for WASa, WASb, WASc, OMW, glycerol and WOC. In the case of AP, the experiments were performed at a working volume of 50 $\mathrm{mL}$, and only $20 \mathrm{~mL}$ of mineral medium was added without any other source of water. Additionally, in a second trial with WOC as the substrate, three different batches were performed with a substrate-toinoculum ratio adjusted to $0.5,0.6$ and 0.9 (see section 2.3 for definition of this ratio). The $\mathrm{pH}$ in the bottle was measured at the beginning and end of each experiment.

Regarding the determination of biogas composition and the produced VFA concentrations, gas and liquid samples were taken at regular interval times directly from the bottles for analysis. On the one hand, the gas composition, including $\mathrm{H}_{2}, \mathrm{CH}_{4}$ and $\mathrm{CO}_{2}$, was determined by gas chromatography (GC). An Agilent Technologies 7820A GC equipped with a G3591-81136 (1.83 $\mathrm{m} \times 2 \mathrm{~mm}$, Porapak Q packing, mesh size $60 / 80$ ) was used. The thermal conductivity detector (TCD) was set at $200^{\circ} \mathrm{C}$, while the injector valve box was set at $250^{\circ} \mathrm{C} . \mathrm{N}_{2}$ was used as carrier gas. The initial oven temperature was set at $70^{\circ} \mathrm{C}$ for $2 \mathrm{~min}$, followed by a temperature ramp of $20^{\circ} \mathrm{C} \mathrm{min}-1$ until reaching $240^{\circ} \mathrm{C}$.

On the other hand, liquid samples were taken to determine acetic acid (HAc), propionic acid (HPr), butyric and isobutyric acids ( $\mathrm{HBt}$ and $\mathrm{HiBt}$ ) and valeric and isovaleric acids (HVc and HiVc) using a GC (Agilent Technologies 7820A) equipped with a flame ionization detector (FID). Samples were filtered with $0.45 \mu \mathrm{m}$ pore filters to eliminate the biomass present in the sample. Then, $200 \mu \mathrm{L}$ of each sample was transferred to a chromatography vial to which $800 \mu \mathrm{L}$ of a stabilizing solution composed of $\mathrm{HgCl}(0.5 \mathrm{~g})$, hexanoic acid $(0.54 \mathrm{~mL}$, internal standard) and phosphoric acid $(5 \mathrm{~mL}, 100 \%)$ was subsequently added. The equipment used was a 7820 A GC (Agilent Technologies) equipped with a DB FFAP column $(30 \mathrm{~m} \times 0.25$ $\mathrm{mm} \times 0.25 \mu \mathrm{m}$ ) and a flame ionization detector (FID). The GC method used helium as the carrier gas with a split ratio of 10:1. The initial oven temperature was set at $85^{\circ} \mathrm{C}$ and held for 1 minute, followed by a

temperature ramp of $3^{\circ} \mathrm{C} \mathrm{min}-1$ until reaching $130^{\circ} \mathrm{C}$. Subsequently, a second ramp of $35^{\circ} \mathrm{C} \mathrm{min}{ }^{-1}$ was applied until reaching $220^{\circ} \mathrm{C}$. FID was set at $250^{\circ} \mathrm{C}$.

\subsection{Calculations}

The cumulative $\mathrm{H}_{2}$ production $\left(\mathrm{mmol} \mathrm{H}_{2}\right.$ ) was calculated as the total gas production $\left(\mathrm{CH}_{4}, \mathrm{CO}_{2}\right.$ and $\mathrm{H}_{2}$ ) and the concentration of $\mathrm{H}_{2}$ in the headspace. The $\mathrm{H}_{2}$ production yield was calculated as the quotient of 
gas produced ( $\mathrm{mL}$ of $\mathrm{H}_{2}$ ) by the consumed substrate (grams of VS) [28].

The degree of acidification was used to evaluate the acidogenic potential. It was calculated as the sum of each produced VFA (expressed as COD) divided by the total initial substrate (in COD) as described by Gameiro et al. [20]. The productivity of VFAs was calculated as the quotient of the amount of VFAs produced by the consumed substrate (in $\mathrm{g} \mathrm{COD} \mathrm{g} \mathrm{COD}^{-1}$ ), whereas the volumetric VFA production rate was calculated by linear regression of the total VFA concentration versus time ( $\left.m g \operatorname{COD~L}^{-1} h^{-1}\right)$, as reported by Bengtsson et al. [8].

As the VFA composition represents an important parameter for further uses as PHA precursors, the quality of the acidified waste was determined in terms of the odd-to-even VFA ratio. This ratio was defined as the sum of odd-equivalent carboxylic acids (HPr and HVc) divided by the sum of evenequivalent carboxylic acids (HAc, HBt, HiBt and HiVc). In this sense, VFA concentrations measured by GC (section 2.4) were then expressed as COD theoretical equivalents (HAc, 1.06; $\mathrm{HPr}, 1.51 ; \mathrm{HBt}$ and $\mathrm{HiBt}, 1.81$; $\mathrm{HVc}$ and HiVc, 2.04) according to Kumar and Mohan [29].

\subsection{Biomass enrichment for PHA production}

An enriched PHA-producing culture was obtained in a $16 \mathrm{~L}$ sequential batch reactor (SBR) using cycles of $12 \mathrm{~h}$ under a feast/famine strategy. Each cycle consisted of the following phases: settling (60 min), effluent withdrawal (2 min), idle (20 min), feeding (17 min), and reaction (620 min). The medium was aerated and stirred continuously during the reaction time. SRT and hydraulic retention time (HRT) were maintained at 4 and 1 day, respectively.

During the start-up, the SBR was inoculated with $9 \mathrm{~L}$ of activated sludge $\left(6 \mathrm{~g} \mathrm{VS} \mathrm{L}^{-1}\right)$ from a municipal WWTP (Rubí, Catalonia, Spain). The reactor was fed a standard mineral medium designed to supply a $\mathrm{C} / \mathrm{N} / \mathrm{P}$ ratio of 100/5/1 (on a weight basis). The carbon source had a composition of HAc $\left(28.3 \mathrm{~g} \mathrm{~L}^{-1}\right)$, $\operatorname{HPr}\left(31.4 \mathrm{~g} \mathrm{~L}^{-1}\right), \mathrm{HiBt}\left(1.2 \mathrm{~g} \mathrm{~L}^{-1}\right), \mathrm{HBt}\left(8.7 \mathrm{~g} \mathrm{~L}^{-1}\right)$, and HVc acid $\left(5.8 \mathrm{~g} \mathrm{~L}^{-1}\right)$ to emulate the fermented winterization oil cake. PHAs were extracted and analysed as described by Montiel-Jarillo et al. [30].

\section{Results And Discussion}

\subsection{Comparison of the effect of the inoculum conditioning methods on VFA bioconversion and $\mathrm{H}_{2}$ production}

To achieve favourable conditions for acidogenic fermentation, methanogenic activity should be inhibited [31]. Inoculum conditioning methods, such as heat-shock, acid and alkali treatments, have been shown to effectively repress methanogenic activity [14]. Therefore, these three methods were evaluated to identify the optimal treatment for our purposes. In this case, glucose and cellulose were used as model substrates. 
Figure 1A shows the degree of acidification (white dots) for each pre-treatment conditioning method using glucose as the substrate. The highest degree of acidification was obtained for heat shock (39 \pm $2 \%$ ), followed by the alkali pre-conditioning method ( $35 \pm 2 \%$ ), while the lowest degree of acidification (22 $\pm 1 \%$ ) was obtained for acid pre-conditioning. In this sense, O-Thong et al. [14] and Zhang et al. [26] reported that heat-shock conditioning was the most preferable method for suppressing methanogenic activity, while the results for the acid and alkali conditioning methods were contradictory between the two works. However, Ren et al. [32] reported the following order for the degree of acidification: alkali> heatshock> acid conditioning, which is in agreement with our results.

A similar trend was observed when cellulose was used as the substrate (Figure 1B): heat-shock preconditioning gave a degree of acidification of $26 \pm 1 \%$, while alkali and acid conditioning methods gave acidification values of $22 \pm 1 \%$ and $12 \pm 1 \%$, respectively. A lower degree of acidification was obtained with cellulose than with glucose because it is a more complex substrate than glucose, and its hydrolysis by anaerobic microflora is more difficult [33].

Regarding VFA fermentation products, Figure 1 also depicts the VFA composition in the fermented liquid in terms of COD (bars). For both substrates, the distribution of VFA depended on the conditioning method used. For example, for heat-shock and alkali conditioning, the highest concentrations corresponded to $\mathrm{HAc}$ and $\mathrm{HBt}$ acids, while the concentrations of HiBt and HVc acids were lower. Kumari and Das [13] and 0-Thong et al. [14] also reported HAc and HBt as the major soluble fermentation products for the heatshock conditioning method using sucrose and glucose as substrates, respectively. However, other soluble fermentation products, such as HPr and HiBt, were also produced, indicating that the acid-forming pathway might dominate the metabolic flow $[13,14]$. In the case of cellulose, the highest VFA concentration was for HAc for all cases, but HBt, HPr and HiBt were also present, as previously reported $[33,34]$.

$\mathrm{H}_{2}$ production yields were also calculated to compare the effect of the different inoculum conditioning treatments. The highest $\mathrm{H}_{2}$ yield was obtained with the heat-shock-treated inoculum $\left(40.6 \mathrm{~mL} \mathrm{H}_{2} \mathrm{~g}^{-1} \mathrm{VS}\right)$, followed by the acid and alkali treatments (23.2 and $21.76 \mathrm{~mL} \mathrm{H}_{2} \mathrm{~g}^{-1} \mathrm{VS}$, respectively). Kumari and Das [13] reported similar results when comparing the $\mathrm{H}_{2}$ production of glucose using different conditioned inoculums (heat-shock, acid, alkali and freeze drying), achieving the maximum $\mathrm{H}_{2}$ production for the heatshock treatment. Additionally, O-Thong et al. [14] reported better $\mathrm{H}_{2}$ yields for heat-shock conditioning against alkali treatment.

\subsection{Acidogenic potential of different wastes following acidogenic fermentation}

\subsubsection{Acidogenic fermentation}

After determining that heat-shock conditioning treatment was the best for suppressing the methanogenic activity of the inoculum, batch experiments were performed to evaluate the acidogenic potential of different wastes. Figure 2 shows the time-course profile of VFA production yields for all substrates. It can 
be appreciated that the time needed to achieve the maximum VFA concentration is different for each waste.

Three different WAS samples obtained at three different SRTs, 2, 7 and 14 days, were assessed. WAS biodegradability was also enhanced by heat shock in order to pre-hydrolyse the organic fraction. The highest VFA yield was obtained for WASa (SRT $=2 \mathrm{~d})\left(0.75 \pm 0.08 \mathrm{~g} \mathrm{COD} \mathrm{g}^{-1}\right.$ VS between days 4-6 in Figure 2), which was higher than that obtained by Huang, C. et al. [35] (0.53 $\mathrm{g} \mathrm{COD} \mathrm{g}^{-1} \mathrm{VS}$ ) by adjusting the pH to 10 and using nitrite as pre-treatment to increase biodegradability. Huang et al. [36] ( $\left.0.43 \mathrm{~g} \mathrm{COD} \mathrm{g}^{-1} \mathrm{VS}\right)$ and Huang, X. et al. [37] ( $0.31 \mathrm{~g} \mathrm{COD} \mathrm{g}^{-1}$ VS) used biosurfactants or only alkaline pre-treatments. Moreover, the VFA yields for WASb and WASc were lower than those achieved with WASa. For WASb, the maximum VFA yield was observed between days 10 and 12 of fermentation (ca. $0.33 \pm 0.06 \mathrm{~g} \mathrm{COD} \mathrm{g}^{-1}$ VS, Figure 2), while for WASc, the highest value was achieved between days 6 and 8 of fermentation (ca. $0.3 \pm 0.1 \mathrm{~g} \mathrm{COD} \mathrm{g}^{-1} \mathrm{VS}$, Figure 2). These results were foreseeable since it is supposed that the lower the SRT is, the higher the biodegradability of the sludge and thus better acidogenic potential [38].

A high VFA yield was obtained from OMW fermentation ( $\left.0.62 \pm 0.11 \mathrm{~g} \mathrm{COD} \mathrm{g}^{-1} \mathrm{VS}\right)$, which was similar to that obtained for WASa. In the case of OMW, degradability was also enhanced by heat pre-treatment, and the results were higher than those reported by Dionisi et al. [39] ( $\left.0.36 \mathrm{~g} \mathrm{COD} \mathrm{g}^{-1} \mathrm{VS}\right)$. However, the results obtained in our study are very similar to the VFA conversion yields reported by Campanari et al. [9], but those authors used a previous step of solid-liquid separation and different dilutions for OMW fermentation.

Apple pomace (AP) and WOC exhibited very similar VFA yields of $0.21 \pm 0.05$ and $0.24 \pm 0.02 \mathrm{~g} \mathrm{COD} \mathrm{g}^{-1}$ VS, respectively. To the best of our knowledge, this is the first time WOC was assessed as a substrate for acidogenic fermentation. Regarding AP, only a few studies have reported the use of AP towards VFA production (see, for example, [23]). Currently, AP, as well as WOC, are used for the production of enzymes, aromas, animal feed, polyphenols, biosurfactants, etc. [40,41]. This study suggests that AP and WOC may be used as substrates for their bioconversion into VFAs under acidogenic fermentation. Glycerol fermentation resulted in the lowest VFA bioconversion yield $\left(0.17 \pm 0.02 \mathrm{~g} \mathrm{COD} \mathrm{g}^{-1} \mathrm{VS}\right)$, which is very similar to the results reported by Silva et al. [10]. A higher conversion yield for glycerol was found in the work published by [42] ( $0.29 \mathrm{~g}$ total acids $\left.\mathrm{g}^{-1} \mathrm{glycerol}\right)$, but fermentation was performed using iodoform as a methanogenic inhibitor and at thermophilic temperature $\left(55^{\circ} \mathrm{C}\right)$, which seems to boost the production of VFAs. Moreover, the bioconversion of glycerol was diverted to other carboxylic acids (caproic and heptanoic).

\subsubsection{Degree of acidification}

Figure $3 \mathrm{~A}$ depicts the results of the net degree of acidification and $\mathrm{H}_{2}$ yield for each fermented waste. The highest net degree of acidification was observed for WASa (69 $\pm 1 \%)$, which was higher than the results obtained by Li et al. [43] (55-40\%), Kumar and Mohan [29] (37.9\%) or Silva et al. [10] (31\%). The degrees of acidification for WASb and WASc are in the range of those reported in previous studies $(27 \pm 1 \%$ and 
$29 \pm 1 \%$, respectively). The difference between the degree of acidification of the 3 sludges could be due to high biodegradability of the sludge with a low SRT (WASa) since relatively high fermentable organic carbon availability favours VFA production; unfortunately, none of the studies mentioned above state the SRT of the WAS samples used for fermentation. The net degree of acidification for the OMW was $48 \pm$ $1 \%$. This result is significantly higher than that presented by Silva et al. [10] (13.6\%). However, in that study, no pre-treatment method was applied to the OMW. In contrast, there were also higher degrees of acidification for other OMWs (53 - 68\%) [20,44]. However, in those studies, complex and expensive pretreatments such as electrocoagulation and even dilution were employed to decrease the phenolic compounds present in the OMWs, which are supposed to inhibit the bioconversion of the organic matter into VFAs at concentrations over $5 \mathrm{~g} \mathrm{~L}^{-1}$. Glycerol was found to be the waste with the lowest degree of acidification (16 $\pm 1 \%$ ), and this value is in line with previous reports [10,45]. However, in our study, only the bioconversion of glycerol into VFAs was considered, although other authors suggested that under acidogenic fermentation, glycerol may be mainly fermented into other soluble metabolites, such as ethanol and 1,3-propandiol [24].

Interestingly, WOC showed a higher net degree of acidification (22 $\pm 1 \%)$ than that achieved with glycerol and was very similar to that obtained for AP $(19 \pm 1 \%)$. In this study, any pre-treatment was employed for WOC, so further investigations could be focused on enhancing WOC acidogenic potential for its valorization into other value-added products, different from lipases and sophorolipids.

The production of VFAs as soluble metabolites during acidogenic fermentation is coupled to the production of $\mathrm{H}_{2}$; nevertheless, the presence of VFAs directly influences $\mathrm{H}_{2}$ yields (Figure 3A). It has been reported that, either dissociated or undissociated, VFAs affect bacterial growth; undissociated VFAs can diffuse into the cell where they become dissociated due to the intracellular $\mathrm{pH}$, releasing $\mathrm{H}^{+}$in the cytoplasm creating an imbalance that affects the metabolic activity and leads to an increase in the energy required for cellular maintenance, which lowers the available energy for cell growth. On the other hand, the dissociated form of acids increases the ionic strength of the medium, producing cell lysis [46].

In general, low VFA production can be favourable for $\mathrm{H}_{2}$ production, but under high production, the process may be inhibited, suppressing $\mathrm{H}_{2}$ yields. Under such consideration, it could be expected that the substrates that exhibited a relatively low bioconversion into VFA might result in a relatively high $\mathrm{H}_{2}$ yield; however, as can be observed in Figure 3A, this was not true in all cases. For example, glycerol was the substrate with the lowest degree of acidification and the highest $\mathrm{H}_{2}$ yield $\left(10.6 \pm 0.2 \mathrm{~mL} \mathrm{H}_{2} \mathrm{~g}^{-1} \mathrm{VS}\right)$; notwithstanding, the amount of VFAs produced by using AP was very low, and its $\mathrm{H}_{2}$ yield was very similar to that obtained for OMW and WASc. This could be due to its high bioconversion into HBt followed by HAc. Zhao et al. [47] reported that concentrations of HBt close to $4.0 \mathrm{~g} \mathrm{~L}^{-1}$ cause the inhibition of bacterial $\mathrm{H}_{2}$ production, and in our experiments, the $\mathrm{HBt}$ concentration was $3.8 \mathrm{~g} \mathrm{~L}^{-1}$. Moreover, it was previously observed that the presence of $\mathrm{HBt}$ had a stronger effect against $\mathrm{H}_{2}$ production than $\mathrm{HAc}$ [48] and that the stoichiometric yield of $\mathrm{H}_{2}$ was higher for $\mathrm{HAc}$ than for $\mathrm{HBt}$, as $4 \mathrm{~mol}$ of $\mathrm{H}_{2}$ can be produced for each mol of glucose when HAc is the final product, but only $2 \mathrm{~mol}$ of $\mathrm{H}_{2}$ are synthesized 
when $\mathrm{HBt}$ is produced [19]. A low $\mathrm{H}_{2}$ yield $\left(3.6 \pm 0.5 \mathrm{~mL} \mathrm{H}_{2} \mathrm{~g}^{-1} \mathrm{VS}\right)$ was measured for WOC despite its degree of acidification being very similar to that for AP. This could be a consequence of the high production of HPr as an end product, as it was previously demonstrated that $\mathrm{HPr}$ can decrease $\mathrm{H}_{2}$ yields due to its $\mathrm{H}_{2}$-consuming pathway $[19,26]$.

The bioconversion of WASb and WASc into VFA was very similar, but their $\mathrm{H}_{2}$ yields were $4.1 \pm 0.6$ and $3.0 \pm 0.2 \mathrm{~mL} \mathrm{H}_{2} \mathrm{~g}^{-1} \mathrm{VS}$, respectively (Figure $3 \mathrm{~A}$ ). Such a difference could be due to the high amount of HPr produced after WASc fermentation, which might decrease $\mathrm{H}_{2}$ production, as mentioned above. WASa was the substrate with the highest degree of acidification, and therefore, its $\mathrm{H}_{2}$ yield was the lowest $(2.6 \pm 0.1$ $\mathrm{mL} \mathrm{H} \mathrm{g}^{-1} \mathrm{VS}$ ). However, a discrepancy was observed regarding the results obtained for the OMW. Although its bioconversion in VFA was high, the observed $\mathrm{H}_{2}$ yield obtained was higher than expected (4.3 $\pm 0.5 \mathrm{~mL} \mathrm{H}_{2} \mathrm{~g}^{-1} \mathrm{VS}$ ), which was very similar to the result obtained for AP even though the degree of acidification of AP was twice as low as that of OMW. Such a result could be due to the production of HAc as a major fermentation product.

\subsubsection{VFA composition}

The composition and the odd-to-even ratio of the VFA matrix obtained after fermentation (Figure 3B) strongly determine the potential valorization of each waste product [20]. High odd-to-even ratios are of greater interest because they increase the production of PHA copolymers such as P(HB-co-HV), which are a more attractive bioplastic than the homopolymer PHB due to its better thermo-mechanical properties and a wider range of applications [20]. The odd-to-even ratios obtained for the tested substrates at the point of maximum degree of acidification were as follows: WASa, 0.28; WASb, 0.25; WASc, 0.33; OMW, 0.01 ; glycerol, 0.15 ; WOC, 0.86; and AP, 0.01 .

When the acidogenic fermentation results for each waste were analysed in terms of the VFA composition (Figure 3B), AP and OMW were of little interest as fermentation mixtures if they have to be further used as precursors for PHA production. The VFAs formed in the fermentation of both substrates were almost entirely HAc, which has been widely described to synthesize PHB monomers. PHB is the most widely known PHA; however, it has been demonstrated that the copolymer P(HB-co-HV) has better mechanical properties [20], as explained before. Likewise, in the OMW fermentation liquid, the dominant and almost sole VFA produced was HAc (98.4 \%) (Figure 3B). Although some other authors reported a great amount of HAc during OMW fermentation [9, 20,44,49], the results presented herein are higher than those of any other report. The presence of $\mathrm{HPr}, \mathrm{HBt}, \mathrm{HiBt}$ and $\mathrm{HVc}$ was almost negligible ( $<1 \%)$, while in other studies, it accounted for approximately $20 \%$ of total VFAs.

Although the odd-to-even ratio for AP was the same as that for OMW (0.01), their fermented liquid compositions were very different. AP was composed of a mixture of $\mathrm{HBt}$ and $\mathrm{HAc}$, which are even-carbon fatty acids. The most abundant VFA was HBt, followed by HAc (56.6 and 36.4\%, respectively) (Figure 3B). $\mathrm{HPr}, \mathrm{HVc}$ and HiVc were almost negligible $(<1 \%)$, and only $6 \% \mathrm{HiBt}$ acid was observed. These results are 
similar to the VFA composition reported by Doi et al. [50] using rhizosphere microflora, where HBt was also found to be the predominant fatty acid, followed by HAc. Feng et al. [23] also reported the presence of $\mathrm{HAc}$ and $\mathrm{HBt}$ as the main liquid end-products, with the difference that HAc was the main fatty acid synthesized $(65 \%)$ with a very low concentration of $\mathrm{HPr}$.

The main product of glycerol fermentation was HAc (Figure 3B), as previously found by other authors [10, 42], but there were contrasting results for the HPr fraction. We found am HPr content of $12 \%$, as described by Silva et al. [10], but Forrest et al. [42] found HPr in a low amount $(<1 \%)$, and [51] described it as the dominant VFA.

The results for all WAS samples were very similar, with an odd-to-even ratio between 0.25 and 0.33 . The most abundant VFA was HAc (40-60\%), followed by HPr (15-20\%) (Figure 3B). Such results are similar to those of previous studies that identified that HAc accounted for the highest percentage of the total VFAs produced after WAS fermentation [36, 38, 43, 52]. The presence of $\mathrm{HBt}, \mathrm{HiBt}$ and $\mathrm{HVc}$ was also detected but at a low percentage. Kumar and Mohan [29] reported different VFA compositions when working at different $\mathrm{pH}$ conditions, concluding that the higher alkaline $\mathrm{pH}$, the higher the chain of fatty acids (as valeric) produced; however, when the initial pH was 7 (as in our study), the composition achieved was similar to that presented here, with acetic and propionic acids as the dominant VFAs. These results suggest that WAS may be a potential feedstock for PHA copolymer P(HB-co-HV) production.

Interestingly, WOC was proven to be an attractive precursor for PHA production, as its VFA composition exhibited the highest odd-to-even ratio among all the evaluated wastes. Thus, the presence of HPr may result in the enhancement of PHA characteristics, as the HV content can be enhanced due to the incorporation of HV units. HPr was the dominant VFA (43.7\%), followed by HAc (37.8\%), and $\mathrm{HBt}, \mathrm{HiBt}$ and HVc were present in at the same low proportion ( 6\%) (Figure 3B).

\subsection{PHA synthesis from VFAs obtained from winterization oil cake}

Acidification tests were repeated with a new batch of WOCs to confirm the interesting results described above. Varying the substrate:inoculum ratio from 0.5 to 0.9 led to similar results after 7 days of digestion. VFA yields ranged from $0.16-0.18 \mathrm{~g} \mathrm{COD} \mathrm{g}^{-1} \mathrm{VS}$ with a degree of acidification ranging from 16 to $18 \%$, slightly lower than in the initial experiments, probably due to the shortest digestion time (here, it was decided to run the batch experiment for 7 days instead of 18 days). However, the odd-to-even ratio was between 1.2-1.3, higher than previous results $(0.86)$. As mentioned before, the literature reports odd-toeven ratio values below 1 [20] and a degree of acidification ranging up to 35 or $43 \%$ for oil industry wastes $[39,49]$.

Using these results as a reference, a synthetic mixture of VFAs, similar to that obtained from WOC fermentation, was fed into an SBR system for PHA biomass enrichment as described in Montiel-Jarillo et al. [30]. After a steady state was attained, biomass samples were obtained for determination of their PHA content (in g C-PHA g ${ }^{-1}$ C-biomass) and composition (HB and HV monomers). The results were compared to the initial biomass, as depicted in Figure 4. 
Initial biomass presented a composition of $0.018 \mathrm{~g} \mathrm{C} \mathrm{PHA} \mathrm{g}^{-1} \mathrm{C}$. The PHA concentration rapidly increased to 0.42 and $0.64 \mathrm{~g} \mathrm{C} \mathrm{PHA} \mathrm{g}^{-1} \mathrm{C}$. This system allowed for reaching high PHA values in short periods of time compared to other systems previously described for oil industry wastes such diverse lignocellulosic materials like pruning residues with a final content of $32 \%$ [53].

The PHA composition in both samples (at 6 and 9 days of SBR operation) showed a similar content of $30 \% \mathrm{PHB}$ and $69 \%$ PHV. The use of a mixture of VFAs with a high proportion of HAc and HPr has been shown to promote the formation of $\mathrm{P}(\mathrm{HB}-\mathrm{co}-\mathrm{HV})$ copolymer units [54]. HPr is the main precursor of propionyl-CoA formation, but it is also the precursor of acetyl-CoA generation through various metabolic pathways. The combination of both of these precursors leads to the formation of hydroxyvaleryl-CoA, a precursor of HV units that are part of the HV-HB copolymer. Acetyl-CoA units generated in HPr degradation can be combined to generate hydroxybutyryl-CoA, a precursor to HB [55]. With the obtained PHA composition, it is possible to think that both PHB and PHV are found as copolymer monomers $\mathrm{P}(\mathrm{HB}-$ $\mathrm{co}-\mathrm{HV}$ ). This short experiment proves the feasibility of using the effluent of WOC fermentation as a precursor of a $\mathrm{P}(\mathrm{HB}-\mathrm{co}-\mathrm{HV})$ biopolymer.

\section{Conclusions}

The heat-shock conditioning method for suppression of methanogenic activity shows better results in terms of the degree of acidification of the fermented substrate than the alkali and acid treatments.

The highest degrees of acidification ( 69 and $48 \%$, respectively) were attained for WASa collected from a high-rate activated sludge reactor operated at a low SRT (2 days) and for OMW.

To the best of our knowledge, this is the first time that residual oil cakes such as WOC have been evaluated for their bioconversion into VFAs, exhibiting an odd-to-even ratio of ca. 1.2, leading to a higher proportion of PHV in the total PHA content, which, together with the produced PHB, would allow for obtaining a large amount of the copolymer $\mathrm{P}(\mathrm{HB}-\mathrm{co}-\mathrm{HV})$.

\section{Declarations}

\section{Conflicts of interest/Competing interests}

The authors have no conflicts of interest to declare that are relevant to the content of this article.

\section{Funding}

The authors are grateful for the support received through the Spanish Ministry of Economy and Competitiveness: "HIPATIA: Towards the implementation of the concept of biorefinery and energy selfsustainability in a urban wastewater treatment plant" (CTQ2017-82404-R).

\section{Availability of data and material}


Authors declare all data and materials support their published claims and comply with field standards.

\section{References}

[1] Agustín Martínez, G., Bertin, L., Scoma, A., Rebecchi, S., Braunegg, G., Fava, F., 2015. Production of polyhydroxyalkanoates from dephenolised and fermented olive mill wastewaters by employing a pure culture of Cupriavidus necator. Biochem. Eng. J. 97, 92-100. doi:10.1016/j.bej.2015.02.015

[2] Amulya, K., Jukuri, S., Venkata Mohan, S., 2015. Sustainable multistage process for enhanced productivity of bioplastics from waste remediation through aerobic dynamic feeding strategy: Process integration for up-scaling. Bioresour. Technol. 188, 231-239. doi:10.1016/j.biortech.2015.01.070

[3] Gouveia, A.R., Freitas, E.B., Galinha, C.F., Carvalho, G., Duque, A.F., Reis, M.A.M., 2017. Dynamic change of $\mathrm{pH}$ in acidogenic fermentation of cheese whey towards polyhydroxyalkanoates production: Impact on performance and microbial population. N. Biotechnol. 37, 108-116. doi:10.1016/j.nbt.2016.07.001

[4] Colombo, B., Villegas Calvo, M., Sciarria, T.P., Scaglia, B., Kizito, S.S., D'Imporzano, G., Adani, F., 2019. Biohydrogen and polyhydroxyalcanoates (PHA) as products of a two-steps bioprocess from deproteinized dairy wastes. Waste Manage. 95, 22-31. doi:10.1016/j.wasman.2019.05.052

[5] Perimenis, A., Nicolay, T., Leclercq, M., Gerin, P.A., 2018. Comparison of the acidogenic and methanogenic potential of agroindustrial residues. Waste Manag. 72, 178-185. doi:10.1016/j.wasman.2017.11.033

[6] Zhou, M., Yan, B., Wong, J.W.C., Zhang, Y., 2018. Enhanced volatile fatty acids production from anaerobic fermentation of food waste: A mini-review focusing on acidogenic metabolic pathways. Bioresour. Technol. 248, 68-78. doi:10.1016/j.biortech.2017.06.121

[7] Dahiya, S., Sarkar, O., Swamy, Y. V., Venkata Mohan, S., 2015. Acidogenic fermentation of food waste for volatile fatty acid production with co-generation of biohydrogen. Bioresour. Technol. 182, 103-113. doi:10.1016/j.biortech.2015.01.007

[8] Bengtsson, S., Hallquist, J., Werker, A., Welander, T., 2008. Acidogenic fermentation of industrial wastewaters: Effects of chemostat retention time and $\mathrm{pH}$ on volatile fatty acids production. Biochem. Eng. J. 40, 492-499. doi:10.1016/j.bej.2008.02.004

[9] Campanari, S., E Silva, F.A., Bertin, L., Villano, M., Majone, M., 2014. Effect of the organic loading rate on the production of polyhydroxyalkanoates in a multi-stage process aimed at the valorization of olive oil mill wastewater. Int. J. Biol. Macromol. 71, 34-41. doi:10.1016/j.ijbiomac.2014.06.006

[10] Silva, F.C., Serafim, L.S., Nadais, H., Arroja, L., Capela, I., 2013. Acidogenic fermentation towards valorisation of organic waste streams into volatile fatty acids. Chem. Biochem. Eng. Q. 27, 467-476. 
[11] Esteban-Gutiérrez, J., Garcia-Aguirre, I., Irizar, I., Aymerich, E., 2018. From sewage sludge and agri-food waste to VFA: Individual acid production potential and up-scaling. Waste Manage. 77, 203-212. doi: 10.1016/j.wasman.2018.05.027

[12] Jung, K., Kim, W., Park, G.W., Seo, C., Chang, H.N., Kim, Y.C., 2015. Optimization of volatile fatty acids and hydrogen production from Saccharina japonica: acidogenesis and molecular analysis of the resulting microbial communities. Appl. Microbiol. Biotechnol. 99, 3327-3337. doi:10.1007/s00253-015$6419-2$

[13] Kumari, S., Das, D., 2017. Improvement of biohydrogen production using acidogenic culture. Int. J. Hydrogen Energy 42, 4083-4094. doi:10.1016/j.jijhydene.2016.09.021

[14] O-thong, S., Prasertsan, P., Birkeland, N., 2009. Bioresource Technology Evaluation of methods for preparing hydrogen-producing seed inocula under thermophilic condition by process performance and microbial community analysis. Bioresour. Technol. 100, 909-918. doi:10.1016/j.biortech.2008.07.036

[15] Eryildiz, B., Lukitawesa, Taherzadeh, M.J., 2020. Effect of pH, substrate loading, oxygen, and methanogens inhibitors on volatile fatty acid (VFA) production from citrus waste by anaerobic digestion. Bioresour. Technol. 302, 122800. doi:10.1016/j.biortech.2020.122800

[16] Wang, D., Duan, Y.Y., Yang, Q., Liu, Y., Ni, B.J., Wang, Q., Zeng, G., Li, X., Yuan, Z., 2018. Free ammonia enhances dark fermentative hydrogen production from waste activated sludge. Water Res. 133, 272-281. doi:10.1016/j.watres.2018.01.051

[17] Chen, Y., Xiao, K., Shen, N., Zeng, J.C., Zhou, Y., 2018. Hydrogen production from a thermophilic alkaline waste activated sludge fermenter: Effects of solid retention time (SRT). Chemosphere 206, 101106. doi: 10.1016/j.chemosphere.2018.04.170

[18] Atasoy, M., Owusu-Agyeman, I., Plazab, E., Cetecioglu, Z., 2018. Review: Bio-based volatile fatty acid production and recovery from waste streams: Current status and future challenges. Biores. Technol. 268, 773-786. doi: 10.1016/j.biortech.2018.07.042

[19] Ghimire, A., Frunzo, L., Pirozzi, F., Trably, E., Escudie, R., Lens, P.N.L., Esposito, G., 2015. A review on dark fermentative biohydrogen production from organic biomass: Process parameters and use of byproducts. Appl. Energy 144, 73-95. doi:10.1016/j.apenergy.2015.01.045

[20] Gameiro, T., Sousa, F., Silva, F.C., Couras, C., Lopes, M., Louros, V., Nadais, H., Capela, I., 2015. Olive oil mill wastewater to volatile fatty acids: Statistical study of the acidogenic process. Water. Air. Soil Pollut. 226. doi:10.1007/s11270-015-2311-z

[21] El-Bakry, M., Abraham, J., Cerda, A., Barrena, R., Ponsá, S., Gea, T., Sanchez, A., 2015. From wastes to high value-added products: Novel aspects of SSF in the production of enzymes. Crit. Rev. Environ. Sci. Technol. 45, 1999-2042. doi:10.1080/10643389.2015.1010423 
[22] Jiménez-Peñalver, P., Gea, T., Sánchez, A., Font, X., 2016. Production of sophorolipids from winterization oil cake by solid-state fermentation: Optimization, monitoring and effect of mixing. Biochem. Eng. J. 115, 93-100. doi:10.1016/j.bej.2016.08.006

[23] Feng, X., Wang, H., Wang, Y., Wang, X., Huang, J., 2010. Biohydrogen production from apple pomace by anaerobic fermentation with river sludge. Int. J. Hydrogen Energy 35, 3058-3064. doi:10.1016/j.ijhydene.2009.07.015

[24] Chookaew, T., O-Thong, S., Prasertsan, P., 2012. Fermentative production of hydrogen and soluble metabolites from crude glycerol of biodiesel plant by the newly isolated thermotolerant Klebsiella pneumoniae TR17. Int. J. Hydrogen Energy 37, 13314-13322. doi:10.1016/j.ijhydene.2012.06.022

[25] Buitrón, G., Carvajal, C., 2010. Biohydrogen production from Tequila vinasses in an anaerobic sequencing batch reactor: Effect of initial substrate concentration, temperature and hydraulic retention time. Bioresour. Technol. 101, 9071-9077. doi:10.1016/j.biortech.2010.06.127

[26] Zhang, K., Ren, N., Guo, C., Wang, A., Cao, G., 2011. Effects of various pretreatment methods on mixed microflora to enhance biohydrogen production from corn stover hydrolysate. J. Environ. Sci. 23, 19291936. doi:10.1016/S1001-0742(10)60679-1

[27] Angelidaki, I., Alves, M., Bolzonella, D., Borzacconi, L., Campos, J.L., Guwy, A.J., Kalyuzhnyi, S., Jenicek, P., Van Lier, J.B. , 2009. Defining the biomethane potential (BMP) of solid organic wastes and energy crops: a proposed protocol for batch assays. Water Sci. Technol. 59, 927-934. doi:10.2166/wst.2009.040

[28] Noparat, P., Prasertsan, P., O-thong, S., 2011. Isolation and characterization of high hydrogenproducing strain Clostridium beijerinckii PS-3 from fermented oil palm sap. Int. J. Hydrogen Energy 36, 14086-14092. doi:10.1016/j.jhydene.2011.04.143

[29] Kumar, A. N., Mohan, S. V., 2018. Acidogenesis of waste activated sludge - Biohydrogen production with simultaneous short chain carboxylic acids. J. Environ. Chem. Eng. 6, 2983-2991. doi:10.1016/j.jece.2018.04.032.

[30] Montiel-Jarillo, G., Carrera, J., Suárez-Ojeda, M.E., 2017. Enrichment of a mixed microbial culture for polyhydroxyalkanoates production: Effect of $\mathrm{pH}$ and $\mathrm{N}$ and $\mathrm{P}$ concentrations. Sci. Total Environ. https://doi.org/10.1016/j.scitotenv.2017.01.069

[31] Wainaina, S., Awasthi, L.M.K., Taherzadeh, M-J., 2019. Bioengineering of anaerobic digestion for volatile fatty acids, hydrogen or methane production: A critical review. Bioengineered 10:1, 437-458. doi: 10.1080/21655979.2019.1673937

[32] Ren, N.Q., Guo, W.Q., Wang, X.J., Xiang, W.S., Liu, B.F., Wang, X.Z., Ding, J., Chen, Z.B., 2008. Effects of different pretreatment methods on fermentation types and dominant bacteria for hydrogen production. 
Int. J. Hydrogen Energy 33, 4318-4324. doi:10.1016/j.ijhydene.2008.06.003

[33] Jiang, H., Gadow, S.I., Tanaka, Y., Cheng, J., 2015. Improved cellulose conversion to bio-hydrogen with thermophilic bacteria and characterization of microbial community in continuous bioreactor. Biomass and Bioenergy 75, 57-64. doi:10.1016/j.biombioe.2015.02.010

[34] Lin, C.Y., Hung, W.C., 2008. Enhancement of fermentative hydrogen/ethanol production from cellulose using mixed anaerobic cultures. Int. J. Hydrogen Energy 33, 3660-3667.

doi:10.1016/j.ijhydene.2008.04.036

[35] Huang, C., Liu, C., Sun, X., Sun, Y., Li, R., Li, J., Shen, J., Han, W., Liu, X., Wang, L., 2015. Hydrolysis and volatile fatty acids accumulation of waste activated sludge enhanced by the combined use of nitrite and alkaline pH. Environ. Sci. Pollut. Res. 22, 18793-18800. doi:10.1007/s11356-015-4822-y

[36] Huang, X., Mu, T., Shen, C., Lu, L., Liu, J., 2016. Effects of bio-surfactants combined with alkaline conditions on volatile fatty acid production and microbial community in the anaerobic fermentation of waste activated sludge. Int. Biodeterior. Biodegrad. 114, 24-30. doi:10.1016/j.ibiod.2016.05.014

[37] Huang, X., Shen, C., Liu, J., Lu, L., 2015. Improved volatile fatty acid production during waste activated sludge anaerobic fermentation by different bio-surfactants. Chem. Eng. J. 264, 280-290. doi:10.1016/j.cej.2014.11.078

[38] Xin, X., He, J., Li, L., Qiu, W., 2018. Enzymes catalyzing pre-hydrolysis facilitated the anaerobic fermentation of waste activated sludge with acidogenic and microbiological perspectives. Bioresour. Technol. 250, 69-78. doi:10.1016/j.biortech.2017.09.211

[39] Dionisi, D., Beccari, M., Gregorio, S.D., Majone, M., Papini, M.P., Vallini, G., 2005. Storage of biodegradable polymers by an enriched microbial community in a sequencing batch reactor operated at high organic load rate. J. Chem. Technol. Biotechnol. 80, 1306-1318. doi:10.1002/jctb.1331

[40] Dhillon, G.S., Kaur, S., Brar, S.K., 2013. Perspective of apple processing wastes as low-cost substrates for bioproduction of high value products: A review. Renew. Sust. Energ. Rev. 27, 789-805. doi:10.1016/j.rser.2013.06.046

[41] Ancuța, P., Sonia, A., 2020. Oil Press-Cakes and Meals Valorization through Circular Economy Approaches: A Review. Appl. Sci., 10, 7432. doi:10.3390/app10217432

[42] Forrest, A.K., Sierra, R., Holtzapple, M.T., 2010. Effect of biodiesel glycerol type and fermentor configuration on mixed-acid fermentations. Bioresour. Technol. 101, 9185-9189. doi:10.1016/j.biortech.2010.07.041

[43] Li, X., Peng, Y., Li, B., Wu, C., Zhang, L., Zhao, Y., 2017. Effects of alkali types on waste activated sludge (WAS) fermentation and microbial communities. Chemosphere 186, 864-872. doi:10.1016/j.chemosphere.2017.08.017 
[44] Yarimtepe, C.C., Oz, N.A., Ince, O., 2017. Volatile fatty acid production dynamics during the acidification of pretreated olive mill wastewater. Bioresour. Technol. 241, 936-944.

doi:10.1016/j.biortech.2017.05.173

[45] Tokumoto, H., Tanaka, M., 2012. Novel anaerobic digestion induced by bacterial components for value-added byproducts from high-loading glycerol. Bioresour. Technol. 107, 327-332.

doi:10.1016/j.biortech.2011.12.051

[46] Ciranna, A., Ferrari, R., Santala, V., Karp, M., 2014. Inhibitory effects of substrate and soluble end products on biohydrogen production of the alkalithermophile Caloramator celer: Kinetic, metabolic and transcription analyses. Int. J. Hydrogen Energy 39, 6391-6401. doi:10.1016/j.ijhydene.2014.02.047

[47] Zhao, M., Yan, Q., Ruan, W., Miao, H., Ren, H., Xu, Y., 2010. Effects of butyric acid stress on anaerobic sludge for hydrogen production from kitchen wastes. J. Chem. Technol. Biotechnol. 85, 866-871. doi:10.1002/jctb.2380

[48] van Ginkel, S., Logan, B.E., 2005. Inhibition of Biohydrogen Production by Undissociated Acetic and Butyric Acids. Environ. Sci. Technol. 39, 9351-9356. doi:10.1021/es0510515

[49] Ntaikou, I., Kourmentza, C., Koutrouli, E.C., Stamatelatou, K., Zampraka, A., Kornaros, M., Lyberatos, G., 2009. Exploitation of olive oil mill wastewater for combined biohydrogen and biopolymers production. Bioresour. Technol. 100, 3724-3730. doi:10.1016/j.biortech.2008.12.001

[50] Doi, T., Matsumoto, H., Abe, J., Morita, S., 2010. Application of rice rhizosphere microflora for hydrogen production from apple pomace. Int. J. Hydrogen Energy 35, 7369-7376. doi:10.1016/j.ijhydene.2010.04.173

[51] Yin, J., Yu, X., Zhang, Y., Shen, D., Wang, M., Long, Y., Chen, T., 2016. Enhancement of acidogenic fermentation for volatile fatty acid production from food waste: Effect of redox potential and inoculum. Bioresour. Technol. 216, 996-1003. doi:10.1016/j.biortech.2016.06.053

[52] Yu, L., Zhang, W., Liu, H., Wang, G., Liu, H., 2018. Evaluation of volatile fatty acids production and dewaterability of waste activated sludge with different thermo-chemical pretreatments. Int. Biodeterior. Biodegrad. 129, 170-178. doi:10.1016/j.ibiod.2018.02.008

[53] Davis, R., Kataria, R., Cerrone, F., Woods, T., Kenny, S., O’Donovan, A., Guzik, M., Shaikh, H., Duane, G., Gupta, V.K., Tuohy, M.G., Padamatti, R.B., Casey, E., O'Connor, K.E., 2013. Conversion of grass biomass into fermentable sugars and its utilization for medium chain length polyhydroxyalkanoate (mcl-PHA) production by Pseudomonas strains. Bioresour. Technol. doi:10.1016/j.biortech.2013.10.001

[54] Jiang, Y., Hebly, M., Kleerebezem, R., Muyzer, G., van Loosdrecht, M.C.M., 2011. Metabolic modeling of mixed substrate uptake for polyhydroxyalkanoate (PHA) production. Water Res. 45, 1309-1321. doi: 10.1016/j.watres.2010.10.009 
[55] Kourmentza, C., Kornaros, M., 2016. Biotransformation of volatile fatty acids to polyhydroxyalkanoates by employing mixed microbial consortia: The effect of $\mathrm{pH}$ and carbon source. Bioresour. Technol. 222, 388-398. doi: 10.1016/j.biortech.2016.10.014

\section{Figures}
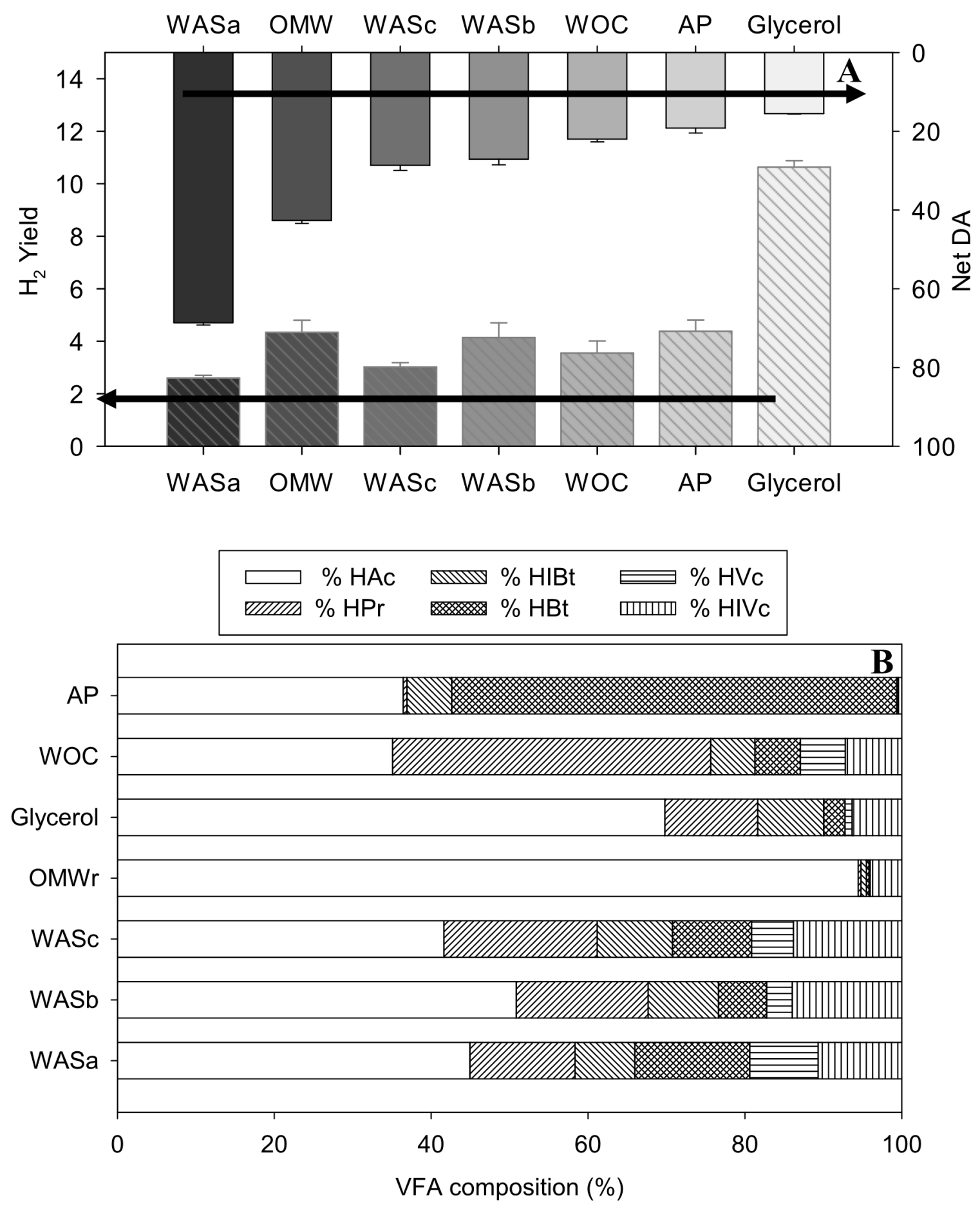
VFA concentrations after acidogenic fermentation using different conditioning methods. White dots represent the degree of acidification (DA) as \%. A) Glucose and B) cellulose.

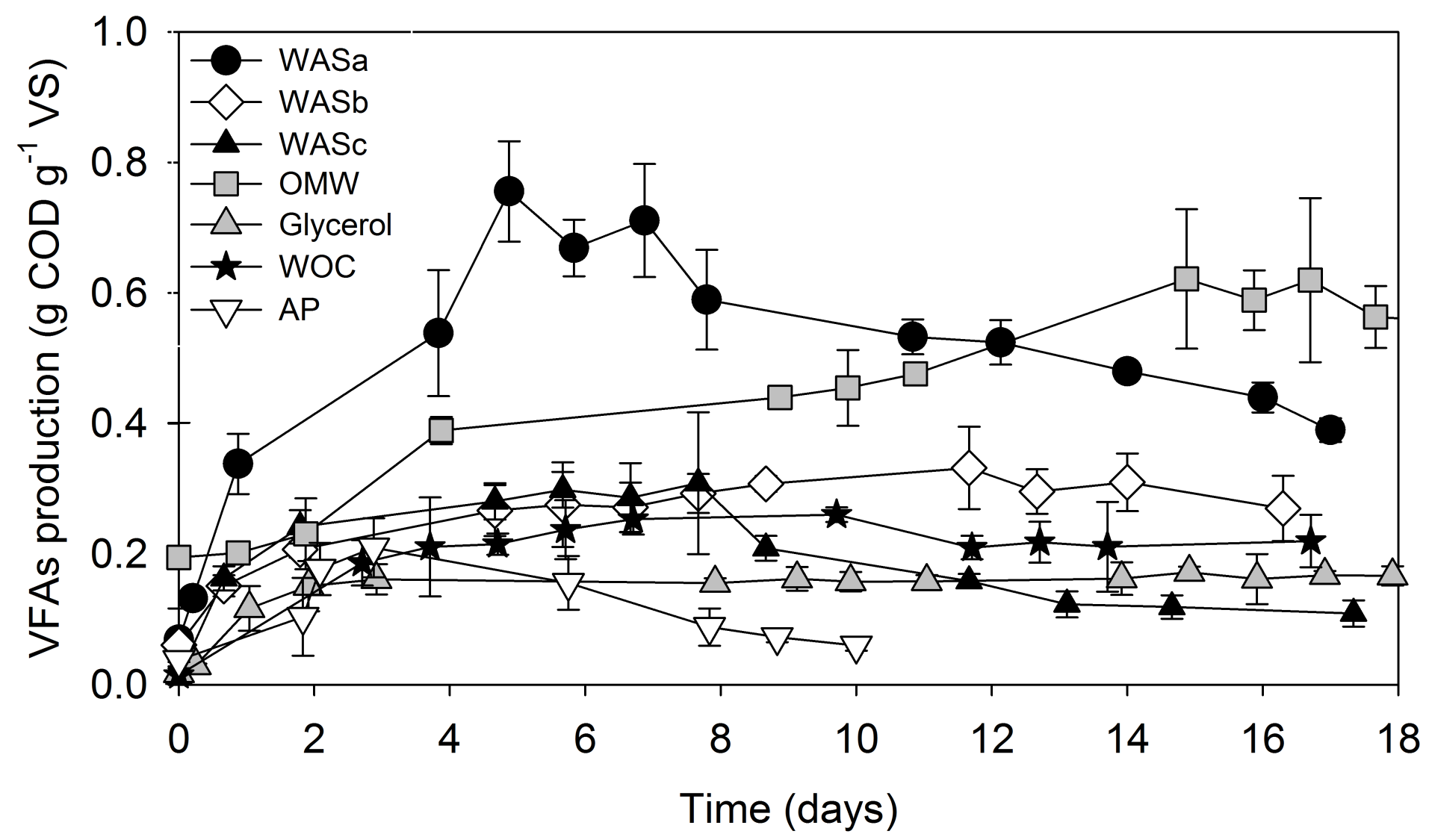

Figure 2

VFA conversion yields in $\mathrm{g}$ of CODsubstrate per $\mathrm{g}$ of VSinoculum over time for different wastes. 

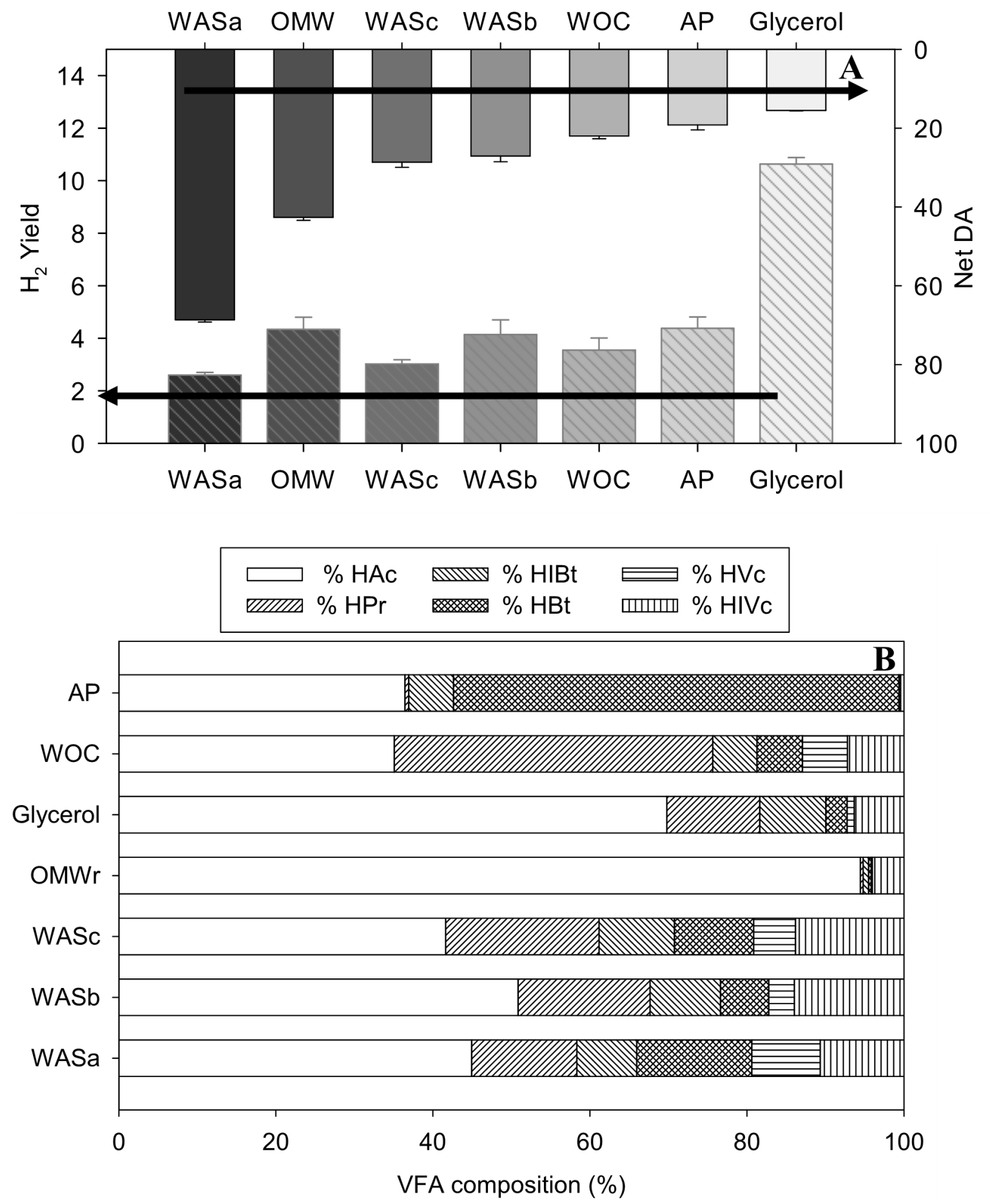

Figure 3

Acidogenic fermentation of different wastes. A) $\mathrm{H} 2$ production yields ( $\mathrm{mL} \mathrm{H} 2 \mathrm{~g}-1 \mathrm{VS}$ ) and net DA (VFA produced, in \%) for each waste. B) Composition of produced VFAs (in \%) for each waste 


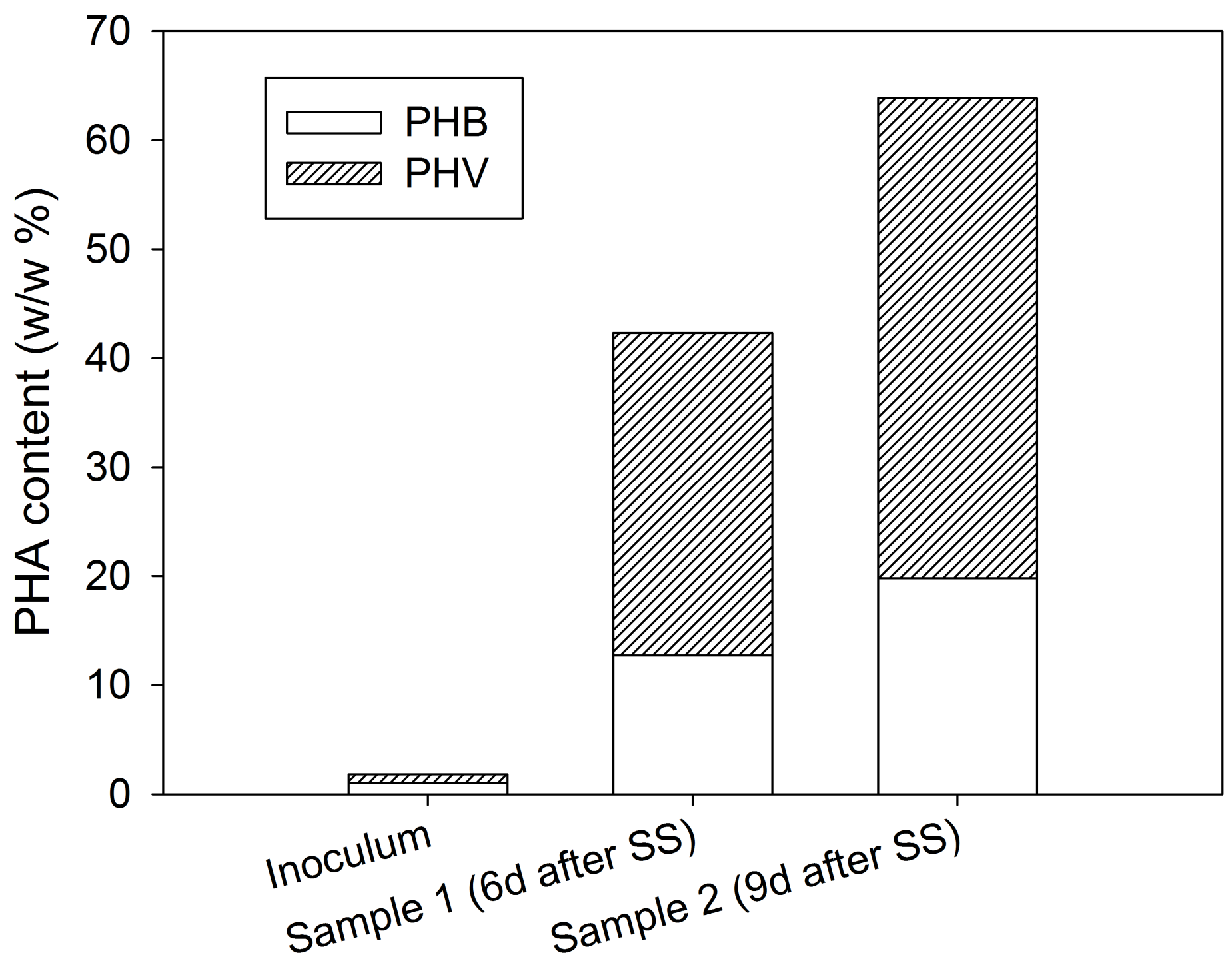

Figure 4

PHA composition in biomass samples from an SBR fed with the VFA mixture obtained from WOC. PHB (black); PHV (grey).

\section{Supplementary Files}

This is a list of supplementary files associated with this preprint. Click to download.

- GraphicalAbstract.docx 